\title{
Publisher Correction to: Influence of Three Gorges Dam and drought on particulate organic carbon flux and its source in the lower Yangtze River
}

\author{
S. Panwar $(i)$ S. Yang
}

Published online: 21 February 2022

(C) The Author(s), under exclusive licence to Springer Nature Switzerland AG 2022

\section{Correction to: Biogeochemistry \\ https://doi.org/10.1007/s10533-022-00889-w}

The PDF version of this originally published article was the uncorrected proof; it has now been replaced by the corrected version.

Publisher's Note Springer Nature remains neutral with regard to jurisdictional claims in published maps and institutional affiliations.

The original article can be found online at https://doi.org/ 10.1007/s10533-022-00889-w.

S. Panwar $(\bowtie) \cdot$ S. Yang

State Key Laboratory of Marine Geology, Tongji

University, Shanghai 200092, China

e-mail: sugandha.panwar@tongji.edu.cn 